\section{Self reported symptoms in children predicted schizophreniform disorder as adults}

Poulton R, Caspi A, Moffitt TE, et al. Children's self-reported psychotic symptoms and adult schizophreniform disorder: a 15-year longitudinal study. Arch Gen Psychiatry 2000 Nov;57:1053-8.

\section{QUESTION: Can self reported symptoms of schizophrenia at 11 years of age predict the risk for schizophreniform disorder at 26 years of age?}

Sources of funding:

Health Research

Council of New Zealand and National Institute of Mental Health.

For correspondence: Dr R Poulton, Dunedin Multidisciplinary

Health and

Development Research Unit, Dunedin School of Medicine, University of Otago, PO Box 913 , Dunedin, New Zealand. Fax +6434795487 .

\section{Design}

Population based cohort study with 15 years of follow up.

\section{Setting}

Dunedin, New Zealand.

\section{Participants}

761 of 789 participants (52\% boys) were interviewed at 11 and 26 years of age. Exclusion criterion was absence of interviews at both ages.

\section{Assessment of risk factors}

Diagnostic Interview Schedule for Children (DISC-C) was used to assess 5 psychotic symptoms in children. Items were scored by the psychiatrist $(0$, no; 1 , yes, likely; and 2, yes, definitely) and summed to obtain a total score (no symptoms, score of 0 ; weak symptoms, score of 1 ; strong symptoms, score $\geqslant 2$ ).

\section{Main outcome measures}

Adult psychopathology was assessed using the Diagnostic Interview Schedule (DIS) for DSM-IV. Interviewers were blinded to previous symptoms. Diagnosis of schizophreniform disorder at 26 years of age required a self report of $\geqslant 1$ hallucination symptoms plus 2 other symptoms (delusions, disorganised speech, catatonic behaviour, or negative symptoms) and $\geqslant 1$ social or occupational impairments in 3 areas (long term unemployment, poor money management, not in a relationship, paranoia, social isolation, or poor grooming). Diagnosis required symptoms to last $\geqslant 1$ month.

\section{Main results}

The prevalence of schizophreniform disorder at 26 years of age was $3.3 \%$. Schizophreniform diagnoses were made in $2 \%$ of the control children compared with $9.5 \%$ of the weak symptom children (odds ratio [OR] $5.1,95 \%$ CI 1.7 to 18.3 ) and $25 \%$ of the strong symptom children (OR 16.4, CI 3.9 to 67.8). Symptoms at 11 years of age did not predict a higher risk of mania or depression at 26 years of age, but there was a weak association with anxiety disorder. The strongest association was with the symptom of hallucinations at 26 years of age (table).

\section{Conclusion}

11 year old children with either weak or strong symptoms of schizophrenia were at higher risk of schizophreniform diagnosis at 26 years of age than children with no symptoms.
Percentage of children with no, weak, or strong psychotic symptoms at 11 years of age diagnosed with schizophreniform disorder at 26 years of age

\begin{tabular}{lcccc}
$\begin{array}{l}\text { Schizophrenia } \\
\text { symptoms at age } \\
26 \text { years }\end{array}$ & $\begin{array}{l}\text { No symptoms } \\
(\mathrm{n}=654)\end{array}$ & $\begin{array}{l}\text { Weak } \\
\text { symptoms } \\
(\mathrm{n}=95)\end{array}$ & $\begin{array}{l}\text { Strong } \\
\text { symptoms } \\
(\mathrm{n}=12)\end{array}$ & $\mathrm{p}$ Value \\
\hline Delusions & $18.7 \%$ & $27.4 \%$ & $41.7 \%$ & 0.007 \\
\hline Hallucinations & $11.3 \%$ & $22.1 \%$ & $41.7 \%$ & $<0.001$ \\
\hline Disorganised speech & $16.6 \%$ & $23.7 \%$ & $41.7 \%$ & 0.009 \\
\hline Catatonic behaviour & $6.9 \%$ & $10.6 \%$ & $33.3 \%$ & 0.003 \\
\hline Negative symptoms & $0.9 \%$ & $2.1 \%$ & $8.3 \%$ & 0.03 \\
\hline
\end{tabular}

\section{COMMENTARY}

Prospective community studies seeking childhood and adolescent predictors of adult psychoses have typically yielded very modest predictive power. This has slowed the development of clinical interventions aimed at preventing psychosis because the target population of such interventions is so difficult to identify. The study by Poulton et al provides provocative results by suggesting that simply asking adolescents 5 questions may prospectively identify those who will develop psychosis.

This is, overall, a methodologically sound study. The results appear credible, especially given the "dose response" relation shown (ie, the more adolescent psychotic symptoms, the higher the risk of adult schizophreniform disorder), the relative diagnostic specificity of the association, and the longitudinal prospective design.

An important issue, however, is the breadth of the diagnoses encompassed by the category of schizophreniform disorder. The authors reported a prevalence of $3.3 \%$, which is very high compared with the best prevalence estimates for schizophrenia and related psychoses, typically below $1.0 \%$. Despite the precautions taken to increase diagnostic accuracy, an issue well discussed by the authors, these adults with schizophreniform disorder probably included those who had various problems that extended beyond schizophrenia and even other schizophrenia spectrum psychoses. Hence, this adult schizophreniform group may include, for example, brief psychoses occurring in patients with personality disorders and may capture a general liability to psychosis.

The implication of this study is that psychotic like symptoms in adolescents should be taken seriously and not prematurely dismissed as a normal age related phenomenon. Asking these 5 questions should probably be part of any systematic mental status examination with adolescents, even with those who do not display overt psychotic symptoms. Moreover, individuals who endorse these symptoms probably warrant continued follow up to monitor the development of severe psychopathology. Finally, these psychotic like symptoms will probably be used to select high risk samples in future clinical trials of interventions aimed at preventing the onset of psychosis.

Marc-André Roy, MD

Nathalie Gingras, MD Université Laval Robert-Giffard Beauport, Québec, Canada 